\title{
Author Correction: Floats with bio-optical sensors reveal what processes trigger the North Atlantic bloom
}

\author{
A. Mignot ${ }^{1,2}$, R. Ferrari ${ }^{1} \& H$. Claustre $^{2}$
}

Correction to: Nature Communications https://doi.org/10.1038/s41467-017-02143-6, published online 15 Jan 2018.

In the original version of this Article, the data accession https://doi.org/10.17882/42182 was omitted from the Data Availability statement.

In the first paragraph of the Methods subsection entitled 'Float data processing', the WET Labs ECO-triplet fluorometer was incorrectly referred to as 'WETLabs ECO PUK'. In the final paragraph of this subsection, the WET Labs ECO-series fluorometer was incorrectly referred to as 'WETLabs 413 ECO-series'.

In the Methods subsection 'Float estimates of phytoplankton carbon biomass', the average particulate organic carbon-bbp ratio of $37,537 \mathrm{mgC} \mathrm{m}^{-2}$ was incorrectly given as $37,357 \mathrm{mgC} \mathrm{m}^{-2}$.

In the second paragraph of the Methods subsection 'Float estimates of population division rates', the symbol for Celsius (C) was omitted from the phrase 'a $10^{\circ} \mathrm{C}$ increase in temperature'.

These errors have now been corrected in the PDF and HTML versions of the Article.

Published online: 04 May 2018

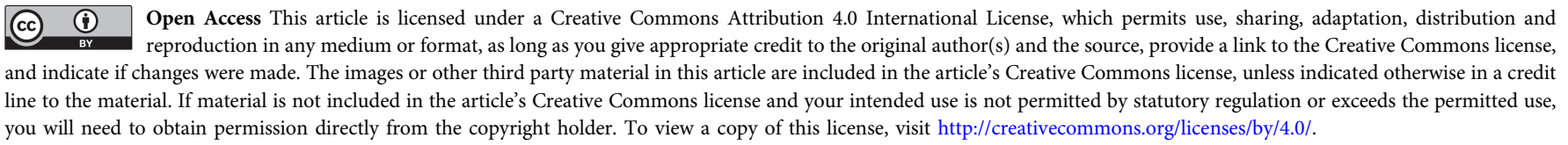

(C) The Author(s) 2018

\footnotetext{
${ }^{1}$ Massachusetts Institute of Technology, Cambridge, MA 02139, USA. ${ }^{2}$ Laboratoire d'Océanographie de Villefranche (LOV), UPMC Univ. Paris 06, CNRS, UMR 7093, Sorbonne Universités, 181 Chemin du Lazaret, 06230 Villefranche-sur-mer, France. Correspondence and requests for materials should be addressed to A.M. (email: mignot@obs-vlfr.fr)
} 